\title{
Investigating fading impact on AODV, OLSR and DSDV protocols in NS3
}

\author{
Hanene Brahmia \\ Laboratoire Réseaux et Systèmes LRS \\ Dept. computer science \\ BADJI Mokhtar Annaba University \\ Annaba, Algeria \\ hanenebrahmia@gmail.com
}

\author{
Cherif Tolba \\ Laboratoire Réseaux et Systèmes LRS \\ Dept. computer science \\ BADJI Mokhtar Annaba University \\ Annaba,Algeria \\ ctolba@yahoo.fr
}

\begin{abstract}
Vehicular communication is an emerging research topic that has not been satisfied yet.Vehicular Ad hoc NETwork, VANET is a system that provides warning messages,road traffic information and advertisement data to drivers.Although It is a domain were the realisation of real experimentations is very expensive and may be dangerous so simulations are the most adapted investigation method to these situations.In our study we used Network Simulator 3 to investigate the influence of the NAKAGAMI fading on the network performances of the three routing protocols AODV,DSDV, and OLSR. Packet Loss ratio and mean delay augmentations were analysed for every protocol in different node densities..
\end{abstract}

Keywords: VANET, routing protocols, AODV, ITS, DSDV, OLSR, NAKAGAMI..

\section{Introduction}

Vehicular ad hoc networks have been an attractive research field to thousands of researchers and manufacturers due to the demand of road users that are now more exigent in terms of comfort, entertainment and safety. In recent decades, ensuring road safety has become a major challenge, as road traffic crashes cause a large number of deaths around the world. Intelligent transportation systems are enriched due to the integration of on board units like the several equipments deployed to ensure connectivity: Global Positioning System (GPS), sensors, antennas and the emerging technology using Light Emitting Diodes (LED) [1]. That equipments allow the vehicles to communicate with each other directly (vehicle to vehicle V2V) and provides traffic information to drivers or keeping him aware of the surrounding environment like other lanes, road side signs or traffic lights. The vehicles can also communicate via or with the infrastructure (V2I communication). Objects in the road can be either an obstacle or a relaying node in the vanet architecture. The trucks and the buildings are one of the most distracting obstacles that causes non line of sight (NLOS) situations[2].Since vehicles are moving with some behaviours: speed, acceleration, deceleration or sudden brake that may cause serious problems. The communication links might be broken and re-established several times per second and so the topology is changing frequently; a well-healing strategy is then a great challenge. In urban 
areas the density of vehicles is usually higher and causes signal interferences. On the other hand, in rural areas low density can cause travel delays due to weak mesh between nodes. When the speed of vehicles increases in highways links establishment and maintenance will be a harder task. The behaviour of the transmitted radio waves also depends on the environment.It can be affected by several phenomenas like : Scattering, polarization, reflection, absorption, diffraction and refraction. Signal fading affects also the routing protocol's mechanism it may causes delay and drives the packets to be lost[3].There is a set of distributions that models the fading in wireless networks[4]. NAKAGAMI which is a statistical one, gives more accurate results.in this paper we investigate the impact of NAKAGAMI fading on the behaviour of the three routing protocols that are: AODV (Ad hoc On demand Distance Vector), OLSR (Optimized Link State Routing) and DSDV (Dynamic Destination-Sequenced Distance Vector) .The paper is organised as follows. Section II is devoted to VANET architecture, its principal features and major challenges then routing protocols will be presented in section III. The propagation models will be discussed in section IV. While the simulation setup of our study and the results and discussions will be devoted in section V and VI respectively. Finally, section VII concludes this paper.

\section{Vanet overview}

An overview of vehicular ad hoc networks is presented here, describing it's architecture, principal features and challenges.

\subsection{VANET Architecture}

VANET or Vehicular Ad-Hoc Networks are a subclass of MANET Mobile Ad-Hoc Networks that are a mesh of interconnected nodes that can communicate without the necessity of a fixed infrastructure. Figure. 1. Presents the most common wireless networks.

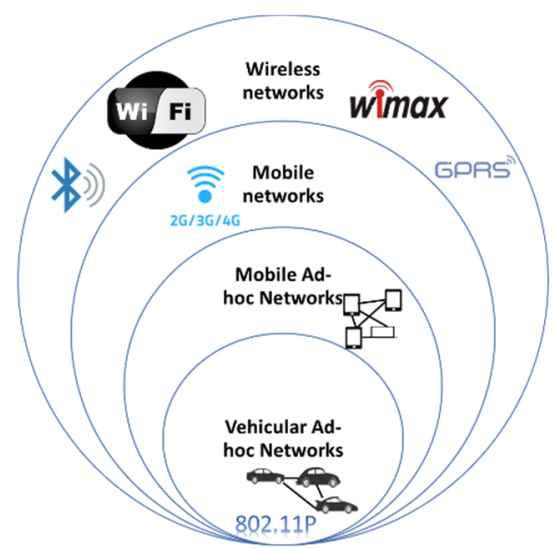

Fig 1. Vanet and wireless networks. 
The node of a mobile ad-hoc network might be a smart phone, a laptop or a wireless printer, while in VANET it can be a truck, a car, or even buses and so on. They can communicate with each other $\mathrm{V} 2 \mathrm{~V}$ to exchange information on the road, broadcast warnings or advertisements. While this network may have fixed entities as Road Side Units (RSU) that manages traffic information and gather technical data about vehicles V2I like speed, direction or destination. The whole architecture is presented in Figure.2.

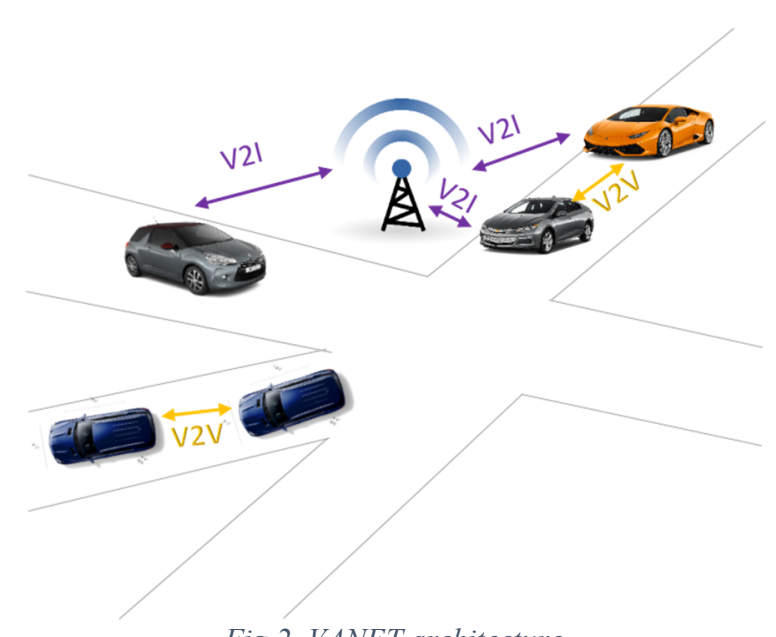

Fig 2. VANET architecture

The network then is divided into two modules:

- The study of the vehicle behaviour without its environment that is the microscopic level.

- The macroscopic level, when the entire surround environment is studied.

\subsection{Principal features of vehicular networks}

In spite of the affiliation of VANET to MANET, it has some specificities and differences from mobile networks that can be resumed in Figure. 3 and discussed below:

- High dynamicity: The vehicles move with certain speed and dynamicity especially in highways where the speed is usually over $100 \mathrm{~km} / \mathrm{h}$.

- Large and quickly scalable network: The nodes like we have said before might be cars, trucks, buses and two wheels that travel together in the road, at pick hours the number of nodes can be huge and a bigger network might be formed quickly.

- Predictable and directional mobility: Vehicular ad-hoc networks may be distinguished from their subclass mobile networks by their predictable mobility where the movements of the vehicles are oriented and non-random.

- No energy limitation: One of the most challenging problems in mobile and sensor networks is the energy while it is an advantage in VANETs, where the nodes generate energy when moving.

Some specifications might be the cause of a lot of problems; some of them are the research challenges presented below. 


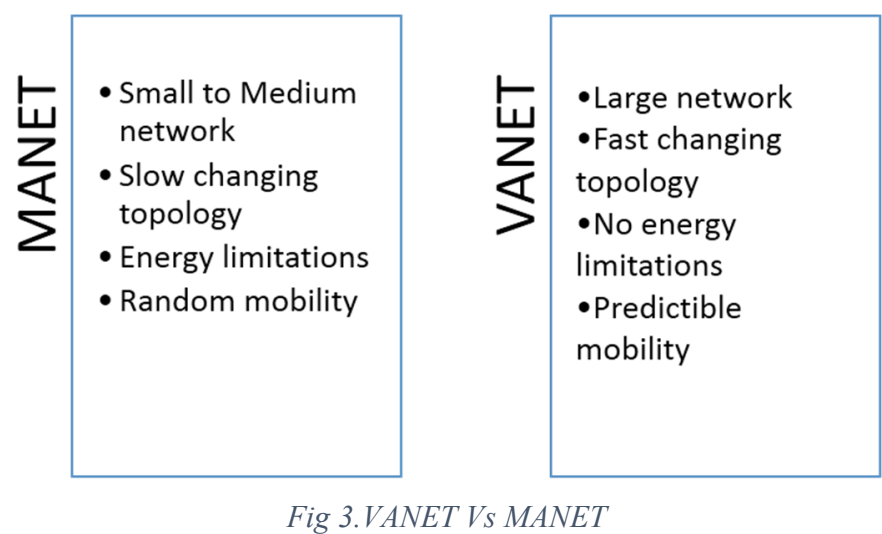

\subsection{Vehicular networks' Challenges}

There are a lot of challenges in VANET that researchers have to solve.This paper will resume some of them, but the research fields are not limited to the following.

- Routing issues and optimizations: The frequently changing topology affects directly communication links and break them, what makes the establishment of a solid connection between vehicles a great challenge.

- Collision avoidance and congestion control: The network is quickly scalable and can be very large what causes traffic jam,non line of sight situations and road accidents.

- Simulating the networks: Since the realisation of real experiments is an expensive and critical experience, where the implementation of the solutions in the real world can cause accidents, the use of an adequate simulator is necessary. To simulate a vehicular network we need two simulators: traffic and network simulator. There are many tools to do the task where the selection of the most adequate one depending on the scenario and the requirements is somehow difficult.

\section{Routing Protocols}

The existence of many MANET routing protocols does not involve as many vehicular ad hoc routing protocols. Some of them does not take in consideration vehicular network specificities or suppose a random movement while it is directed and oriented. Even for those that are suitable for VANET the obtained results and performances cannot reflect the reality.

For this purpose those protocols were studied, compared and ameliorated to be adapted to the vehicular networks [5],[6],[7],[8],[9].

\subsection{Routing issues for vehicular ad-hoc networks}

Due to the rapidity of link establishment or destruction between nodes, low or high density and road obstacles. Routing protocols will face many problems, from where we can mention:

- Local maximum problem: When the nodes cannot find the next hop to forward the message. 
- Limited buffers: Where the messages are ignored due to the lack of space in the buffer, caused by the huge number of packets to be transmitted under time condition.

- Delay and overheads: Some protocols such reactive ones take much time to establish new routes while other ones uses many control packets what produces delay or submerge the network.

- Common solution: The different densities in different areas influence the algorithms and strategies of protocols.

This is the cause of the variation of simulation results depending on scenarios. Protocols that fail in some areas can perform better in other.

\subsection{Routing for VANET}

The routing strategy must take in consideration the bandwidth capacity, the number of nodes and network resources, and have to ensure a reliable path to route the data and maintain those routes. Table 1. Resumes the preferable areas, advantages and limitations of several routing protocols. The protocols were classified according to [10] in five classes: topology (reactive, proactive or hybrid) localisation, cluster, broadcast and geocast while in [11] they have been categorised depending on their message dissemination strategy: unicast, broadcast, multicast or geocast and cluster. In unicasting technique the messages are transmitted individually based on topology. The routes or next hops are maintained in a routing table of each vehicle, in two methods:

- Reactive (routes created on demand) like Ad hoc On-demand Distance Vector (AODV)[12]

- $\quad$ Proactive (routes updated periodically) such Destination Sequence Distance Vector (DSDV)[13] and Optimised Link State Routing protocol (OLSR) [14] that uses shortest path algorithm to provide a single route without loop to the destination which is stored in the routing table.

Unicasting can also be based on the position of the vehicle that is collected from GPS or other positioning systems like GPSR, GSR, GPCR. Broadcasting routing protocols are the most used for safety applications, they are divided into five classes :traffic (DVCAST)[15], area, location, cluster or probability. Cluster based routing protocols divides the network into smaller regions and delegate a cluster head that serves as a collector node that collects all data messages from his zone and as a bridge that transmits to other cluster heads in the other zones. Multicast is like broadcast technique but here the concept of groups is introduced, so instead of broadcasting to all nodes a zone of relevance is chosen, with a forwarding zone where packets are forwarded, not flooded. Multicasting is also sub categorized into topology, or location-based. In this document, our interest is on DSDV, AODV and OLSR protocols. The mechanism of each one is detailed below:

\subsubsection{AODV Ad-hoc On-demand Distance Vector}

Ad-Hoc On-demand Distance Vector is a reactive protocol, which means that it, establishes route when needed, rather than the routing tables in each node that must be updated in every topology change. Researchers give this protocol lot of interest, interpreted by the huge number of papers that presents its ameliorations in different phases [16]. 


\subsubsection{DSDV Destination Sequence Distance Vector}

DSDV implements a distance vector strategy that uses to shortest path and guarantee free loop routes. A sequence number labels each entry in the routing table with total number of hops from source to destination.

\subsubsection{OLSR Optimised Link State Routing}

Despite of DSDV, OLSR maintains a table of all possible routes to each node in the network what may cause network congestion. The routing tables are broadcasted in every topology change.

Table 1. Routing protocols advantages and limitations

\begin{tabular}{|c|c|c|c|c|c|}
\hline categories & Sub categories & $\begin{array}{l}\text { Most } \\
\text { popular } \\
\text { protocols }\end{array}$ & $\begin{array}{l}\text { Preferred } \\
\text { scenarios }\end{array}$ & Advantages & Limitations \\
\hline \multirow{3}{*}{$\begin{array}{l}\text { Topology } \\
\text { based }\end{array}$} & Proactive & OLSR & Urban & $\begin{array}{l}\text { Desirable to use } \\
\text { in a dense } \\
\text { network }\end{array}$ & $\begin{array}{l}\text { Bandwidth } \\
\text { consumption by } \\
\text { unused paths }\end{array}$ \\
\hline & Reactive & AODV & Urban & $\begin{array}{l}\text { Reduces memory } \\
\text { requirements }\end{array}$ & $\begin{array}{l}\text { Takes time to } \\
\text { establish a route }\end{array}$ \\
\hline & Hybrid & TORA & Highway & $\begin{array}{l}\text { Reduce network } \\
\text { overhead }\end{array}$ & Not scalable \\
\hline \multirow[t]{2}{*}{$\begin{array}{l}\text { Location } \\
\text { based }\end{array}$} & Delay Tolerant & VADD & Urban & High PDR & $\begin{array}{l}\text { If the topology is } \\
\text { changing } \\
\text { quickly, it causes } \\
\text { delay }\end{array}$ \\
\hline & $\begin{array}{l}\text { Non-Delay } \\
\text { Tolerant }\end{array}$ & GPCR & Urban & Good scalability & $\begin{array}{l}\text { Depends on } \\
\text { junction nodes }\end{array}$ \\
\hline Cluster based & & LORA-CBF & Highway & Good scalability & Causes delay \\
\hline \multirow{4}{*}{$\begin{array}{c}\text { Broadcast } \\
\text { based }\end{array}$} & Traffic & DV-CAST & Highway & $\begin{array}{l}\text { Reliable } \\
\text { transmission }\end{array}$ & $\begin{array}{lr}\text { Consume } & \text { large } \\
\text { amount } & \text { of } \\
\text { network } & \\
\text { bandwidth } & \\
\end{array}$ \\
\hline & Area & UMB & Urban & $\begin{array}{l}\text { Can overcome } \\
\text { interference and } \\
\text { higher packets } \\
\text { load }\end{array}$ & $\begin{array}{ll}\text { Waste } & \text { of } \\
\text { bandwidth. }\end{array}$ \\
\hline & Cluster & MDDV & Highway & $\begin{array}{l}\text { Message delivery } \\
\text { reliability }\end{array}$ & $\begin{array}{l}\text { High control } \\
\text { packet overhead }\end{array}$ \\
\hline & Probability & REAR & Highway & Good scalability & $\begin{array}{l}\text { Causes more } \\
\text { delay and high } \\
\text { control packet } \\
\text { overhead. }\end{array}$ \\
\hline $\begin{array}{c}\text { Multicast or } \\
\text { Geocast } \\
\text { based }\end{array}$ & & ROVER & Highway & $\begin{array}{l}\text { reliable } \\
\text { geographical } \\
\text { multicast } \\
\text { routing }\end{array}$ & $\begin{array}{l}\text { High delay and } \\
\text { network } \\
\text { congestion }\end{array}$ \\
\hline
\end{tabular}




\section{Propagation models}

In a wireless environment, the propagation models characterize the way the signals are propagated over the network. Most simulators provides different propagation models to give a better study of the environment. Those models are classified into three types: abstract, deterministic and stochastic. The abstract models are to avoid in transportation system simulations because they cannot reflect the reality. Stochastic ones needs hard mathematical calculations but gives realistic mean. The computational efforts that does the stochastic models are heavy for the machines, for this purpose the middle class is preferred to give near realistic results. A clear comparison between propagation models is given in [14]. Over the time, the attenuation of signals vary depending on several variables such geographical position and radio frequency. It is often modelled as a random process. Fading causes communication failures, here we use NAKAGAMI to study the robustness of routing protocols. Since it is able to implement different levels of fading.

It is a stochastic model, where the signal power obeys a gamma $\Gamma$ distribution with two parameters omega $\omega=\left[x^{2}\right]$ the average fading power and mu $\mu>0$ the severity of fading, where the channel amplitude $x \geq 0$.

The NAKAGAMI Probability Density Function PDF is represented according to equation (1):

$$
f(x ; \mu, \omega)=\frac{2 \mu}{\Gamma(\mu) \omega^{\mu}} x^{2 \mu-d} x \bar{p}^{\frac{\mu}{\omega}} x^{2}
$$

\section{Simulation setup}

Most researches on routing protocols assumes a clear environment.So, the performances are somehow idealised.In our simulation we will expose those signals to fading effects using NAKAGAMI. We compare two performance metrics that are packet loss and mean delay. We will distinguish which of the AODV, OLSR, and DSDV is the most resistant protocol under fading circumstances. The simulation parameters are presented in table 2.

Table 2. Simulation setup

\begin{tabular}{cc}
\hline Platform & Ubuntu 15.10 \\
\hline NS Version & Ns-allinone-3.26 \\
\hline Area & $300 * 1500 \mathrm{~m}$ \\
\hline Routing protocols & Aodv, olsr, dsdv \\
\hline Number of nodes & $10,20,30,40,50$ \\
\hline Mac layer & $802.11 \mathrm{p}$ \\
\hline Fading & Nakagami, none \\
\hline Simulation time & 50 seconds \\
\hline
\end{tabular}




\section{Results and discussion}

Here we work in a low-density area containing ten to fifty nodes, such in highway or rural environment; we focus on two important metrics: packet loss and mean delay to study the fading impact on three protocols from two classes, reactive and proactive. The augmentation of the mean delay varied from 0,01 to 0,21 seconds when applying fading on OLSR. It raises significantly at 20,30, and 40 nodes and decrease again at 50 . The routing strategy of OLSR produces more delay by submerging the network with control packets. It establishes routes that may not be used. In a vehicular network the safety application doesn't need to maintain lot of paths, with all nodes as it need to deliver warnings with less delay and better reliability. With OLSR the augmentation of packet loss under realistic fading circumstances is higher than the other protocols. DSDV protocol performances were less affected by Nakagami fading than OLSR.As it uses shortest path algorithm and the fading is modelled, as a random process, it could not resist its impact. The shortest path is not necessarily the best as we can deduce from the packet loss increase and decrease when exposing DSDV to fading. In figure .4, the invocation of Nakagami fading didn't affected AODV protocol, while it does increase the mean delay of OLSR and DSDV by 0,21 and 0,02 seconds respectively, when the node number is 40 . With 10 nodes the mean delay of the three protocols was dramatically increased than in higher densities.

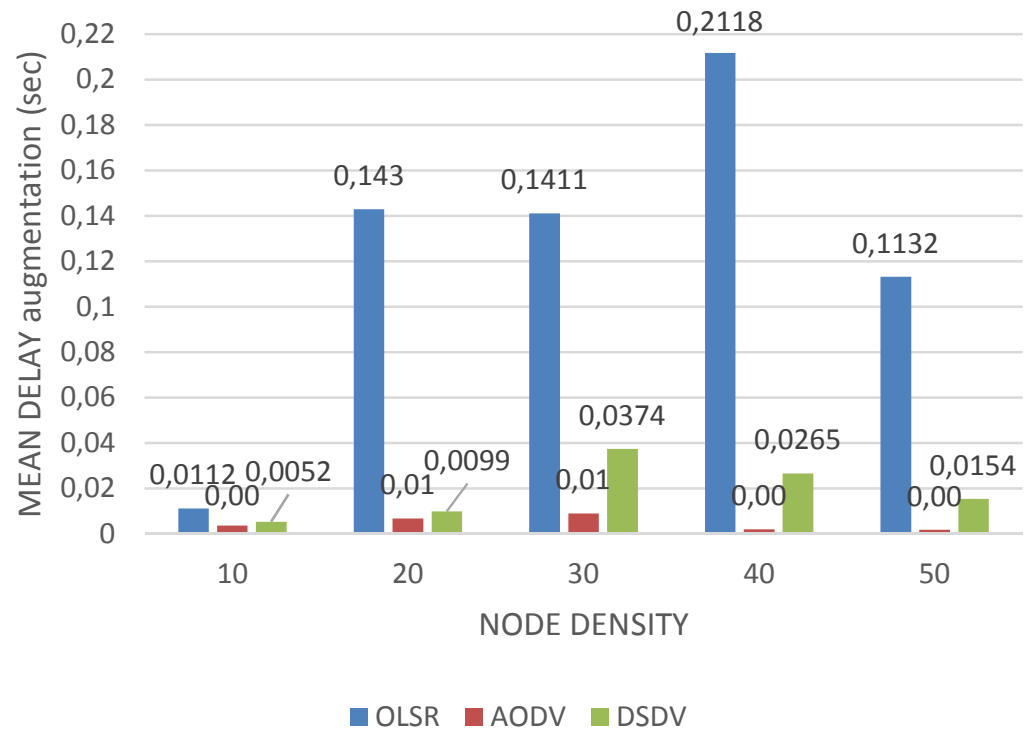

Fig 4.Mean delay increase vs node density 
From figure.5,we can perceive that the reactive protocol AODV outperforms the proactive one (DSDV and OLSR) in the range of 20 to 30 nodes and at 50. At 10 node the DSDV protocol gives its best result what means that is more suited for low density areas like rural environment due to the low neighbourhood messages that have to be sent between nodes. This study should be useful to enhance those three protocols to be adapted to a realistic vehicular scenarios.

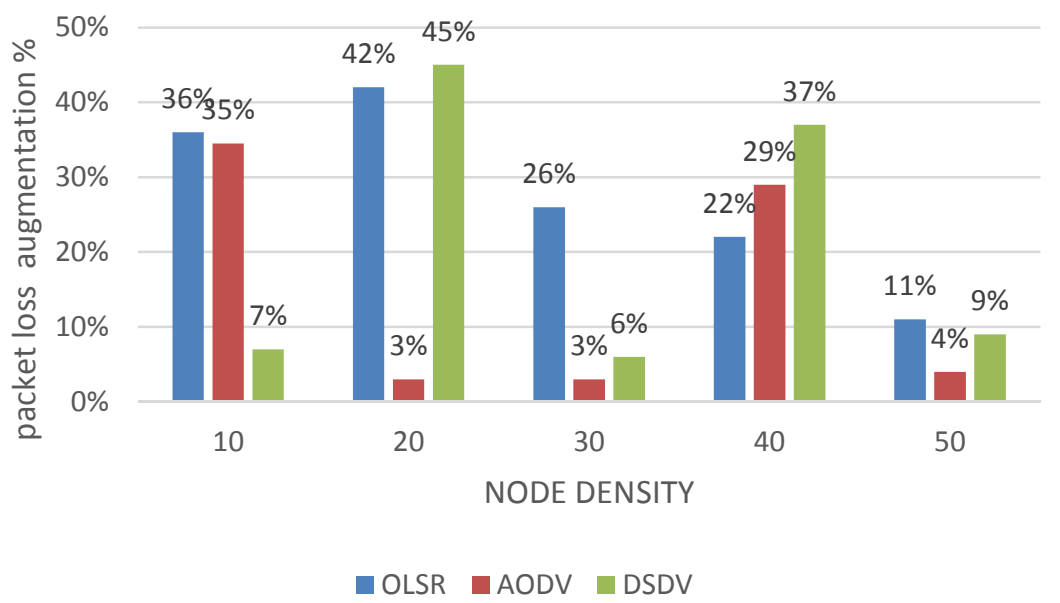

Fig 5. Packet loss increase vs node density

\section{7 conclusion}

In this study we evaluated the performances of AODV,DSDV and OLSR protocols using Nakagami fading in low density areas. We cited some VANET specificities and challenges then we over viewed the routing protocols and classified them according to their routing strategies. The Nakagami fading model was then clarified and applied on the routing protocols. The influence of fading model on the simulation results of VANET may vary depending on road types. The large and multi-lane roads in urban environment or wide ones in highways make a very diverse propagation environment, so many variables must be taken in consideration when simulating each scenario. as futur work we will focus on a specific zone on real map and study the behaviour of some relevant routing protocols beside realistic propagation model.

\section{References}

[1] Prabhu T. N, Adharsh.M, Ashok Kumar M, Gokul Krishna M., and Dhayanithi G : Vehicle to Vehicle Communication using Light Fidelity. International Journal of Computer Applications (0975 - 8887) Vol. 164 , No 2, Apr- 2017.

[2] Abumansoor O, Boukerche. A : A Secure Cooperative Approach for Nonline-of-Sight Location Verification in VANET. IEEE Transactions on Vehicular Technology, Vol. 61, No. 1, JAN- 2012 
[3] Gozalvez J, Sepulcre M,bauza R: Impact of the radio channel modelling on the performance of VANET communication protocols. Telecommun Syst Vol.50, Issue 3, pp 149 - 167, 2012.

[4] Abbas T, Tufvesson F, Karedal J: Shadow Fading Model for Vehicle-to-Vehicle Network Simulations. COST IC1004 2012.

[5] Ali A, and Latha C.A : Performance Analysis of Ad-Hoc Routing Protocols for VANET Using NS2 Simulation. IJCST Vol. 6, Issue 2, April - June 2015.

[6] Maratha B.P, Sheltami T.R and Salah K: Performance Study of MANET Routing Protocols in VANET. King Fahd University of Petroleum \& Minerals Vol. 42, Issue 8, pp 31153126 (2016).

[7] Khattak M, Ahmad G :Implementation of Routing Protocols of MANETs in VANETs Using Route Analysis. International Journal of Engineering Works Kambohwell Publisher Enterprises, 4 (5), pp. 7882 (2017).

[8] Dutta R, Thalore R. : A Review of Various Routing Protocols in VANET. International Journal of Advanced Engineering Research and Science (IJAERS), Vol. 4, Issue-4, Apr- 2017.

[9] Tamilselvi R,Kathiresan V: A review on routing protocols in VANET.International Journal of Advanced Research in Computer Engineering \& Technology (IJARCET) Vol. 6, Issue 9, Sep- 2017.

[10] ur Rehman S, Khan M. A,. Zia T.A,Zheng L : Vehicular Ad-Hoc Networks (VANETs) - An Overview and Challenges. Journal of Wireless Networking and Communications, 29-38 (2013).

[11] Venkatesh, Indra A, Murali R : Routing Protocols for Vehicular Adhoc Networks (VANETs):

A Review. Journal of Emerging Trends in Computing and Information Sciences Vol.5, No.1 Jan- 2014.

[12] Perkins C, Belding-Royer E, Das S, quet : Ad hoc On-Demand Distance Vector (AODV) Routing", RFC 3561, July 2003.

[13] Altayeb M, Mahgoub I. : A Survey of Vehicular Ad hoc Networks Routing Protocols .International Journal of Innovation and Applied Studies ISSN 2028-9324 Vol. 3 No. 3, pp. 829-846 Jul- 2013.

[14] Clausen T.H and Jacquet P : Optimized Link State Routing (OLSR), RFC 3626, October 2003.

[15] Tonguz O. K, Wisitpongphan N and Bai F : DV-CAST: A distributed vehicular broadcast protocol for vehicular ad hoc networks. IEEE Wireless Communications, vol. 17, no. 2, pp. 47-57, Apr- 2010.

[16] Brahmia. H, Tolba .C : Vanet routing protocols: discussion of various Ad-hoc On-demand Distance Vector (AODV) improvements. Proceeding of the The 3rd International Conference on Pattern Analysis and Intelligent Systems, pp. 276-281, OCT- 24-25, 2018.

[17] Stoffers M, Riley G. "Comparing the ns-3 Propagation Models" Modeling,Analysis \& Telecommunication Systems (MASCOTS), IEEE 20th International Symposium,61-67 (2012). 